\title{
High risk injecting behaviour among injectors from Glasgow: cross sectional community wide surveys 1990-1999
}

\author{
A Taylor, D Goldberg, S Hutchinson, S Cameron, R Fox
}

In 1988, the UK Departments of Health gave approval for sterile needles and syringes to be made available to injecting drug users, thus obviating their need to inject with used equipment. ${ }^{1}$ Since then, several hundred needle/ syringe exchange schemes have been established, the incidence of HIV among injectors has been extremely low, ${ }^{2}$ and exchange attenders have been shown to share needles/syringes less frequently than non-attenders. ${ }^{1}$ During the mid-1990s to late $1990 \mathrm{~s}$, however, several observations suggested that injecting risk behaviours might be increasing; between 1997 and 1998, reports of acute hepatitis B infections in injectors throughout the $\mathrm{UK}$ increased by $50 \%,{ }^{2}$ hepatitis C (HCV) infections were prevalent in young injectors ${ }^{3}$ and data from Scotland's Drug Misuse Database and England and Wales's unlinked anonymous surveys of injectors showed high rates of needle/syringe sharing. ${ }^{2}$ We set out to determine the authenticity of these observations by studying sharing behaviours among injectors in Glasgow, a city with one of the highest prevalences of injecting in Western Europe.

\section{Methods and Results}

During 1990-1994 and 1999, voluntary, anonymous, cross sectional surveys of Glasgow's injectors were performed to determine their prevalence of HIV, HCV and associated risk behaviours. ${ }^{3}$ In the 1990-1994 sweeps of the survey, people were eligible for participation if they had injected drugs in the two months before interview; in 1999 respondents were eligible if they had ever injected since January 1990. A multi-site, community wide, sampling strategy-with respondents drawn from both "in treatment" and "out of treatment" settings-was adopted to minimise selection bias. The questionnaire administered by trained interviewers was standardised across survey years. An assessment was made of changes in needle/syringe sharing over successive cross sectional surveys, using multifactorial logistic regression analyses. Data were analysed using S-PLUS software.

Questionnaires were obtained from 2966 individual injectors (duplicate interviews within and between years were removed before analysis). The sample size was approximately 500 in each year between 1990 and 1994 (table 1); 444 respondents were recruited in 1999 but 54 people were eliminated from the analysis because they had not injected in the two months before interview and were therefore not comparable with the previous samples. Seventy one per cent of the total sample were male and $77 \%$ injected at least twice daily; their mean age was 26 years. In the multifactorial regression analyses, after adjusting for behavioural and demographic characteristics (including time since first injection to allow for the shorter injecting careers of those recruited in 1999), a significant decline was observed between years 1990 and 1992, in the risk of reporting injecting with used needles/syringes (a) at least once, (b) at least weekly, (c) with 2 April 2001

Table 1 Characteristics and trends in injecting risk behaviour of 2966 current injecting drug users recruited during a series of cross sectional surveys in Glasgow 1990-1999

\begin{tabular}{|c|c|c|c|c|c|c|}
\hline & $1990(n=503)$ & $1991(n=535)$ & $1992(n=515)$ & $1993(n=505)$ & $1994(n=518)$ & $1999(n=390)$ \\
\hline \multicolumn{7}{|l|}{ Demographic characteristics } \\
\hline \multicolumn{7}{|l|}{ Age (y) (9 non-responses) } \\
\hline mean/median (SD) & $24.4 / 23.5(4.6)$ & $25.6 / 25.1(4.6)$ & $26.1 / 25.2(4.4)$ & $26.5 / 25.9(4.7)$ & $27.8 / 27.2(5.0)$ & $26.1 / 25.4(4.7)$ \\
\hline \multicolumn{7}{|l|}{ Men } \\
\hline$\%(\mathrm{n} / \mathrm{N})$ & $71 \%(356 / 503)$ & $76 \%(407 / 535)$ & $75 \%(385 / 515)$ & $70 \%(354 / 505)$ & $69 \%(355 / 518)$ & $63 \%(247 / 390)$ \\
\hline \multicolumn{7}{|c|}{ Time since onset of injecting (19 non-responses) } \\
\hline mean/median $(\mathrm{SD})$ & $6.4 / 6.0(3.6)$ & $7.2 / 6.9(3.9)$ & $7.7 / 7.9(4.2)$ & $7.9 / 7.9(4.6)$ & $8.7 / 8.8(4.8)$ & $3.8 / 3.3 \rrbracket(2.8)$ \\
\hline \multicolumn{7}{|c|}{ Frequency of injecting drugs in previous six months (13 non-responses) } \\
\hline$<2$ times daily & $23 \%(113 / 499)$ & $22 \%(114 / 530)$ & $17 \%(86 / 515)$ & $23 \%(115 / 504)$ & $29 \%(150 / 515)$ & $29 \%(113 / 390)$ \\
\hline $2-3$ times daily & $43 \%(215 / 499)$ & $45 \%(240 / 530)$ & $37 \%(193 / 515)$ & $42 \%(210 / 504)$ & $43 \%(219 / 515)$ & $41 \%(158 / 390)$ \\
\hline$>3$ times daily & $34 \%(171 / 499)$ & $33 \%(176 / 530)$ & $46 \%(236 / 515)$ & $35 \%(179 / 504)$ & $28 \%(146 / 515)$ & $30 \%(119 / 390)$ \\
\hline \multirow{2}{*}{\multicolumn{7}{|c|}{ Injecting risk behaviour in the previous six months $\dagger$}} \\
\hline & \multicolumn{6}{|c|}{ (a) Injected with used needle/syringe at least once } \\
\hline Prevalence of risk factor (10 non-responses) & $43 \%(215 / 502)$ & $29 \%(155 / 532)$ & $27 \%(138 / 512)$ & $33 \%(164 / 504)$ & $32 \%(166 / 517)$ & $36 \%(141 / 389)$ \\
\hline Adjusted OR $(95 \% \mathrm{CI})$ & $1.92(1.47,2.53)^{\star}$ & $1.09(0.83,1.44)$ & 1.00 (baseline) & $1.39(1.05,1.83)^{\star}$ & $1.54(1.16,2.04)^{\star}$ & $1.60(1.17,2.21)^{\star}$ \\
\hline \multicolumn{7}{|c|}{ (b) Injected with used needle/syringe at least weekly } \\
\hline Prevalence of risk factor (10 non-responses) & $17 \%(84 / 502)$ & $9 \%(47 / 532)$ & $6 \%(30 / 512)$ & $8 \%(42 / 504)$ & $8 \%(40 / 517)$ & $12 \%(46 / 389)$ \\
\hline Adjusted OR (95\% CI) & $2.90(1.86,4.53)^{\star}$ & $1.54(0.95,2.50)$ & 1.00 (baseline) & $1.51(0.93,2.46)$ & $1.55(0.94,2.56)$ & $2.36(1.38,4.02)^{\star}$ \\
\hline \multicolumn{7}{|c|}{ (c) Injected with used needle/syringe from more than one person } \\
\hline Prevalence of risk factor (22 non-responses) & $25 \%(126 / 498)$ & $14 \%(76 / 530)$ & $12 \%(59 / 511)$ & $15 \%(74 / 502)$ & $16 \%(80 / 517)$ & $19 \%(74 / 386)$ \\
\hline Adjusted OR $(95 \% \mathrm{CI})$ & $2.50(1.77,3.54)^{\star}$ & $1.27(0.88,1.85)$ & 1.00 (baseline) & $1.43(0.99,2.08)$ & $1.77(1.22,2.57)^{\star}$ & $1.76(1.16,2.66)^{\star}$ \\
\hline \multicolumn{7}{|c|}{ (d) Injected with used needle/syringe from a casual acquaintanceł } \\
\hline Prevalence of risk factor (14 non-responses) & $12 \%(62 / 501)$ & $7 \%(39 / 529)$ & $4 \%(22 / 512)$ & $8 \%(39 / 504)$ & $9 \%(44 / 517)$ & $10 \%(39 / 389)$ \\
\hline Adjusted OR $(95 \% \mathrm{CI})$ & $3.36(2.01,5.62)^{\star}$ & $1.77(1.03,3.07)^{\star}$ & 1.00 (baseline) & $1.99(1.16,3.43)^{\star}$ & $2.44(1.43,4.19)^{\star}$ & $4.04(2.21,7.38)^{\star}$ \\
\hline
\end{tabular}


more than one person and (d) with a casual acquaintance, in the previous six months (table 1). There was also a significantly increased risk of reporting behaviours (a-d) between 1992 and 1999 (table 1).

\section{Discussion}

Throughout the 1990s the Greater Glasgow Health Board developed the city's needle/ syringe exchange services for its estimated $6000-8500$ injectors $^{4}$; the numbers of needles/ syringes distributed to injectors increased from 136900 in 1990 to 238500 in 1992, 238926 in 1994, 383870 in 1998 and 787524 in 1999. Despite this increase in the provision of injecting equipment, particularly in the late $1990 \mathrm{~s}$, needle/syringe sharing - as measured by several parameters and adjusting for behavioural and demographic characteristics, including time since first injection-increased significantly between 1991 and 1999. These observations confirm other less robust indicators of increased sharing activity and are cause for considerable concern. Conditions for the frequent transmission of $\mathrm{HCV}$ and $\mathrm{HBV}$, and a resurgence of HIV, among injectors are extremely favourable. The reasons why such risks are being taken by a generation of injectors that are different from that of the mid-1980s, need to be elucidated and tackled accordingly. The provision of sterile injecting equipment is essential in preventing the spread of bloodborne infections; however, unless injectors also fully appreciate the dangers of needles/syringe sharing, their preventive effectiveness will be severely attenuated. The Italian experience of the early $1980 \mathrm{~s}^{5}$ - when epidemic spread of HIV, HCV and HBV affected tens of thousands of injectors who had no difficulties in accessing sterile needles and syringes-is a salutary warning.

Funding: this study was supported by grant number SPG8913894 from the Medical Research Council and by the Common Services Agency.

Conflicts of interest: none.

1 Stimson G. AIDS and injecting drug use in the United Kingdom 1987-1993: the policy response and the prevenKingdom 1987-1993: the policy response and the prev
tion of the epidemic. Soc Sci Med 1995;41:699-716.

2 tion of the epidemic. Soc Sci Med 1995;41:699-716. lence of HIV in the United Kingdom, Data to the end of 1998. London, Department of Health, Public Health Laboratory Service, Institute of Child Health (London), Scottish Centre for Infection and Environmental Health 1999.

3 Taylor A, Goldberg D, Hutchinson S, et al. Prevalence of hepatitis $\mathrm{C}$ virus infection among injecting drug users in Glasgow 1990-1996: are current harm reduction strategies working? F Infect $2000 ; 40: 176-83$.

4 Gruer L, Cameron J, Elliott L. Building a city wide service for exchanging needles and syringes. BMF 1993;306:139497.

5 Mesquita F, Telles P, Bustos F, et al. City epidemics and contexts. In: Stimson G, Des Jarlais DC, Ball AL, eds. Drug injecting and HIV infection. World Health Organisation, 1998 . 